Elsevier required licence: (C) <2018>. This manuscript version is made available under the CC-BY-NC-ND 4.0 license http://creativecommons.org/licenses/by-nc-nd/4.0/ 


\title{
Predictive Voltage Control of Direct Matrix Converters with Improved Output Voltage for Renewable Distributed Generation
}

\author{
Jianwei Zhang, Student Member, IEEE, Li Li, Member, IEEE, David G. Dorrell, Senior Member, \\ IEEE, Margarita Norambuena, Member, IEEE, Jose Rodriguez, Fellow, IEEE
}

\begin{abstract}
This paper proposes a predictive voltage control strategy for a direct matrix converter used in a renewable energy distributed generation (DG) system. A direct matrix converter with $\mathrm{LC}$ filters is controlled in order to work as a stable voltage supply for loads. This is especially relevant for the stand-alone operation of a renewable DG where a stable sinusoidal voltage, with desired amplitude and frequency under various load conditions, is the main control objective. Model predictive control is employed to regulate the matrix converter so that it produces stable sinusoidal voltages for different loads. With predictive control, many other control objectives, e.g., input power factor, common-mode voltage and switching frequency, can be achieved depending on the application. To reduce the number of required measurements and sensors, this work utilizes observers and makes use of the switch matrices. In addition, the voltage transfer ratio can be improved with the proposed strategy. The controller is tested under various conditions including intermittent disturbance, non-linear loads and unbalanced loads. The proposed controller is effective, simple, and easy to implement. Simulation and experimental results verify the effectiveness of the proposed scheme and control strategy. This proposed scheme can be potentially used in microgrid applications.
\end{abstract}

Index Terms--Distributed Generation, Matrix Converter, Microgrid, Observers, Predictive Voltage Control, Voltage Transfer Ratio.

\section{INTRODUCTION}

A MODERN interconnected power system can contain HYBRID AC and DC grids, with various power electronic converters interfacing different energy sources [1][2], as shown in Fig. 1. The distributed generators (DGs) are modern components in a grid network and they are interconnected via the point of common coupling (PCC). Energy generation issues are driving the development of renewable energy based DGs and microgrids and these have been the focus of great interest [3][4]. In a similar manner to a

J. Zhang, L. Li are with the University of Technology Sydney, Sydney, New South Wales, 2007, Australia (e-mails: Jianwei.Zhang@uts.edu.au, Li.Li@uts.edu.au).

D. G. Dorrell is with the University of KwaZulu-Natal, Durban, South Africa. (e-mail: d.g.dorrell@gmail.com).

M. Norambuena is with the Universidad Técnica Federico Santa María, Valparaíso, Chile (e-mail: margarita.norambuena@gmail.com).

J. Rodriguez is with the Universidad Andrés Bello, Santiago, Chile (email: jose.rodriguez@unab.cl).

The original manuscript with part of this work was presented in the 9th annual IEEE Energy Conversion Congress and Exposition (ECCE 2017), Cincinnati, Ohio, USA. ECCE manuscript ID: EC-0087. microgrid, a DG can operate in a grid-connected mode or an islanded mode. When operated in the grid-connected mode, the main control objective is the current or power exchange with the utility grid (or microgrid bus). The main control objective during islanded operation is to maintain stable sinusoidal voltages for various loads [5]-[8]. These operating modes depend on system operating conditions, users demand, availability of energy, and utility grid requirement. For both operating modes, a DG should be able to supply electricity in a reliable, secure and economical manner [9]-[11]. To this end, power electronic converters play a critical role [12]. Various power electronic converters, including multilevel converters [13], together with their corresponding control techniques, have been researched for controlling power flow, current and voltage for DG and microgrid applications [14].

This paper mainly focuses on the islanded mode of a renewable DG. At present, a DG or microgrid is an inverterdominated system [7] [15]. However, it is difficult to maintain feed to connected loads, particularly nonlinear loads, at the required voltage and frequency with an inverter [8]. In the literature, research projects on voltage source inverters (VSI) and neutral point clamped (NPC) inverters, with many control methods, have been carried out on uninterrupted power system (UPS) based DGs in order to regulate the output voltage [16] [17]. The LC filters are commonly used in these topics. However, these strategies are only suitable for DC DGs and microgrids. For AC DGs and microgrids, the rectifier stage and DC-link capacitor are required together with an inverter for indirect AC/AC conversion. These will make the system bulky, reduce the lifetime and increase maintenance. In addition, there exists the necessity of the DC link voltage control. Other significant drawbacks of this structure include unidirectional power flow, difficulty in controlling the input power factor, and handling of the input unbalance and intermittent disturbance of the renewable energy sources.

Recent demand for the AC/AC conversion has emerged in the field of DGs and microgrids [18] [19]. A solution for direct $\mathrm{AC} / \mathrm{AC}$ conversion is the matrix converter [20]; this is an alternative to the established indirect $\mathrm{AC} / \mathrm{AC}$ conversion method with a DC link. A direct three-phase matrix converter, as shown in Fig. 2, features compact structure, bidirectional power flow, controllable input power factor (which can be set to unity), regeneration capability, and no energy-storage elements [20]-[22]. In addition, it was reported in [23] that the matrix converter can be used for other conversions (i.e. $\mathrm{AC} / \mathrm{DC}, \mathrm{DC} / \mathrm{AC}$, and $\mathrm{DC} / \mathrm{DC}$ ) to feed various loads such as inductive, capacitive, nonlinear, AC and even DC systems, as 


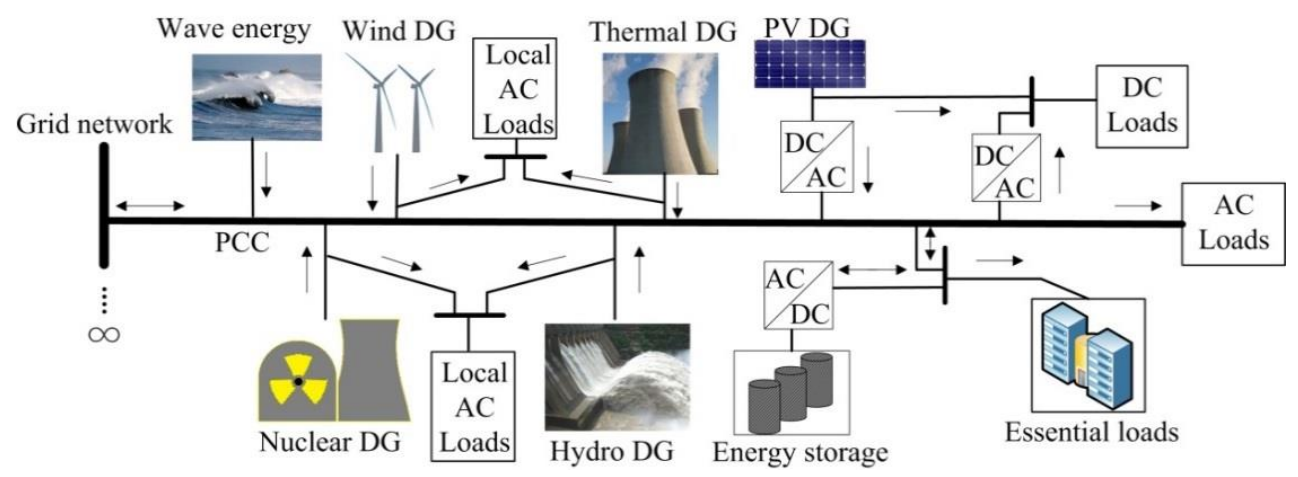

Fig. 1. Diagram of an interconnected power system example involving renewable DGs.

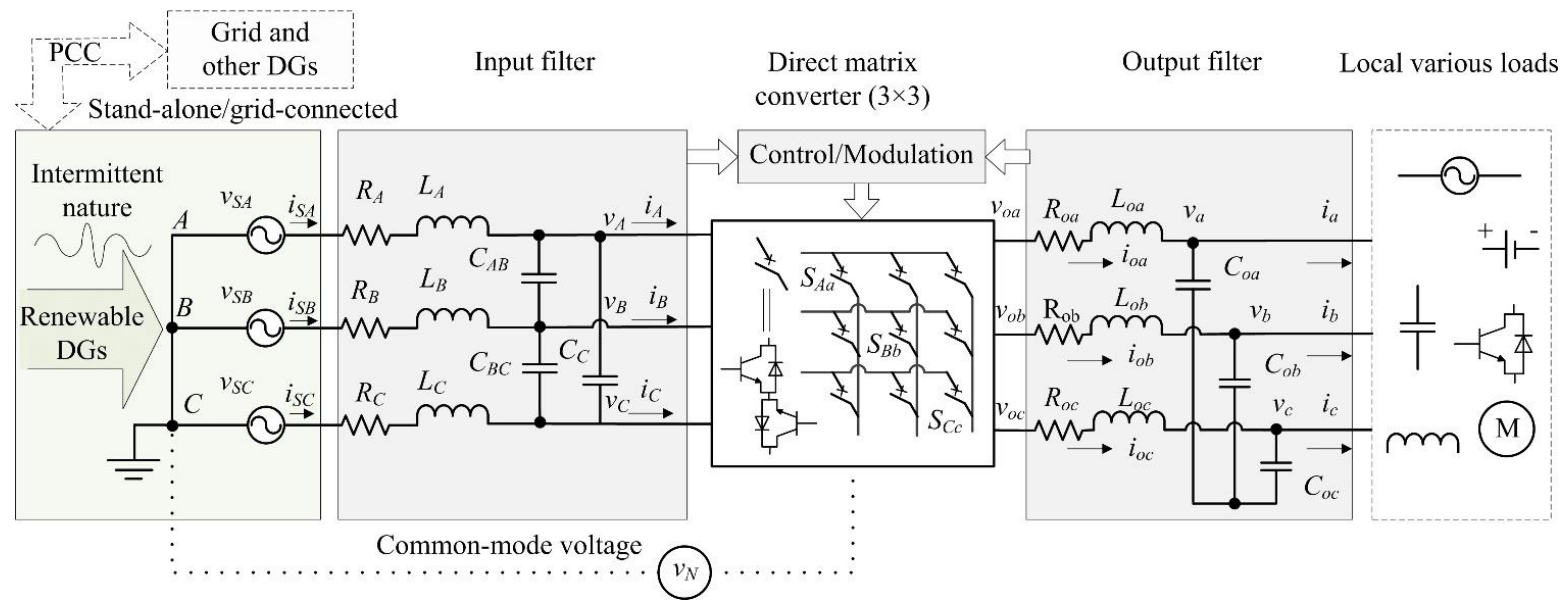

Fig. 3. AC microgrid with renewable DGs and matrix converter.

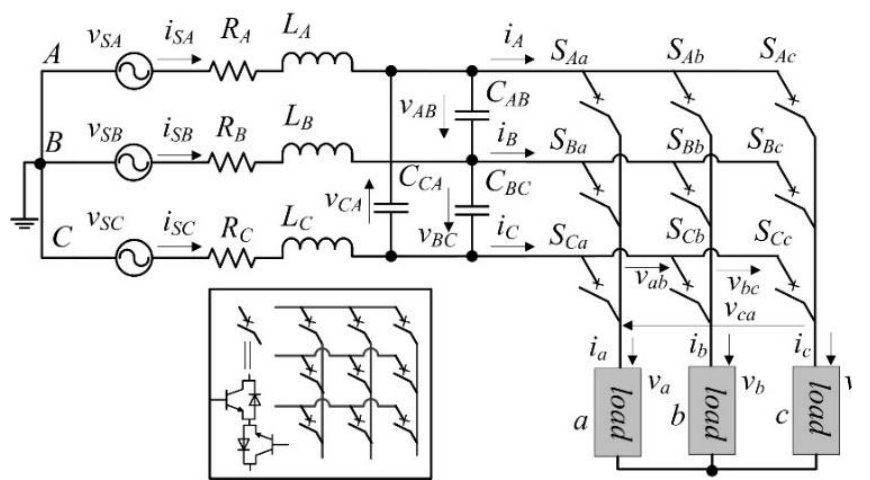

Fig. 2. A three-phase direct matrix converter system with input filters.

shown in Fig. 3. Matrix converters haven been assessed for suitability in many applications [24]-[26]. However, the use of a direct matrix converter in a renewable DG or microgrid remains unexplored.

In terms of control approaches for direct matrix converters, classic modulation methods including scalar modulation and pulse width modulation (PWM) techniques usually are programmed offline; thus, these methods are vulnerable to the system and load variations causing steady-state errors [27]. Space vector modulation (SVM) has been widely researched and applied. However, the voltage transfer ratio (VTR) is limited to below $\sqrt{3} / 2(\approx 0.866)$, which is a known drawback, like most of the other control methods. Most of the control methods are concerned with sinusoidal output currents, so they cannot provide sinusoidal voltages. Furthermore, they cannot handle common-mode voltage which can be detrimental, especially to motor loads. This is one of the main reasons for premature failures in a machine [28].

This paper adopts model predictive control (MPC) to control the output voltages of a matrix converter for the application in the islanded mode of a DG. MPC is a simple and powerful control tool for power converters [29]. This method does not require a modulation stage but can utilize all 27 available matrix converter switch states. MPC utilizes a system model to predict future system behavior and select the optimum switch state by minimizing a predefined cost function. The cost function design in MPC is flexible as it can contain many factors and constraints depending on the specific application and requirements [30]. Some predictive control strategies have been proposed for matrix converters [31]-[33]; however, they are mainly concerned with sinusoidal output currents rather than output voltages. In addition, the issues of the limited VTR persist.

The main contributions of this paper include: (1) a control scheme for a matrix converter interfaced renewable energy DG system is proposed and the DG can be either islanded or grid-connected; (2) instead of controlling output currents, a predictive voltage control strategy for a direct matrix converter is proposed which supplies various loads in an islanded DG system; the output voltage control is achieved by utilizing LC filters; (3) with the proposed predictive voltage control, other control objectives and constraints can be readily considered including common-mode voltage, input power factor and average switching frequency; (4) the VTR is 
improved with the proposed scheme and the number of required sensors is reduced by using observers; and (5) a matrix converter prototype is built to validate the proposed scheme.

The proposed scheme is tested under various conditions including nonlinear loads, unbalanced loads and intermittent disturbance and unbalanced input. The regulated voltage meets the voltage quality set in the IEEE standard: IEEE Std519-2014 [34].

\section{SySTEM PREDICTION MODELS}

\section{A. Matrix Converter Fundamentals}

Bidirectional switches are required in a matrix converter to provide reverse voltage blocking capability and conduct current in both directions. These bidirectional switches are usually constructed by connecting two switches in common emitter or common collector arrangement. As shown in Figs. 2 and 3, a three-phase direct matrix converter consists of nine bidirectional semiconductor switches and forms a $3 \times 3$ switch matrix as expressed in

$$
\begin{gathered}
{\left[\begin{array}{c}
v_{o a} \\
v_{o b} \\
v_{o c}
\end{array}\right]=\left[\begin{array}{lll}
S_{A a} & S_{B a} & S_{C a} \\
S_{A b} & S_{B b} & S_{C b} \\
S_{A c} & S_{B c} & S_{C c}
\end{array}\right]\left[\begin{array}{c}
v_{A} \\
v_{B} \\
v_{C}
\end{array}\right]=S\left[\begin{array}{l}
v_{A} \\
v_{B} \\
v_{C}
\end{array}\right]} \\
{\left[\begin{array}{c}
i_{A} \\
i_{B} \\
i_{C}
\end{array}\right]=\left[\begin{array}{lll}
S_{A a} & S_{A b} & S_{A c} \\
S_{B a} & S_{B b} & S_{B c} \\
S_{C a} & S_{C b} & S_{C c}
\end{array}\right]\left[\begin{array}{l}
i_{o a} \\
i_{o b} \\
i_{o c}
\end{array}\right]=S^{T}\left[\begin{array}{l}
i_{o a} \\
i_{o b} \\
i_{o c}
\end{array}\right]} \\
\sum_{X=A, B, C} S_{X x}=1,(x=a, b, c)
\end{gathered}
$$

where $S$ and its transpose $S^{T}$ are switch matrices. The elements $S_{X x}$ in the switch matrices can be assigned a value of ' 1 ' or ' 0 ' to indicate the 'on' or 'off' state of a switch. Based on the measurements of $v_{A, B, C}$ and $i_{o a, o b, o c}$, the values of $v_{o a, o b, o c}$ and $i_{A, B, C}$ can be calculated respectively, which are used in the prediction models. Matrix converter output voltages and input currents can be controlled by controlling the switch matrices.

The constraints in (3) are applied to exclude the switch states that short-circuit the input terminals (usually voltage sources) and that open-circuit the output terminals (usually inductive loads). Otherwise, overcurrent and overvoltage will be generated which can damage devices. As a result, there are 27 switch states allowable in the matrix which correspond to 27 control actions (finite control set) in MPC.

\section{B. Output LC Filter Models}

The implementation of MPC is based on a system model. According to Fig. 3, the output filters of the matrix converter are modeled as

$$
\left\{\begin{array}{l}
v_{o a}-i_{o a} \cdot R_{o a}-L_{o a} \frac{d i_{o a}}{d t}=v_{a} \\
v_{o b}-i_{o b} \cdot R_{o b}-L_{o b} \frac{d i_{o b}}{d t}=v_{b} \\
v_{o c}-i_{o c} \cdot R_{o c}-L_{o c} \frac{d i_{o c}}{d t}=v_{c}
\end{array}\right.
$$

$$
\left\{\begin{array}{l}
C_{o a} \frac{d v_{a}}{d t}=i_{o a}-i_{a} \\
C_{o b} \frac{d v_{b}}{d t}=i_{o b}-i_{b} \\
C_{o c} \frac{d v_{c}}{d t}=i_{o c}-i_{c}
\end{array}\right.
$$

The variables in (4) and (5) are shown in Fig. 3. The capacitors can be connected in star $\left(C_{A, B}, C\right)$ or delta $\left(C_{A B, B C}\right.$ $\left.C_{C A}\right)$. The feature of the star connection is that the required capacitance is three times $\left(C_{A}=3 C_{A B}\right)$ while the voltage rating is $1 / \sqrt{ } 3$ times $\left(V_{A B}=\sqrt{ } 3 V_{A}\right)$ of that of the delta connection for the equivalent ratings.

In order to simplify the modeling procedure, it is sufficient to consider a single-phase model due to the symmetry of three-phase system. Hence (4) and (5) can be rewritten in the state space model:

$$
\left[\begin{array}{c}
i_{o a} \\
\dot{v}_{a}
\end{array}\right]=F\left[\begin{array}{c}
i_{o a} \\
v_{a}
\end{array}\right]+G\left[\begin{array}{c}
v_{o a} \\
i_{a}
\end{array}\right]
$$

where $F=\left[\begin{array}{cc}-R_{o a} / L_{o a} & -1 / L_{o a} \\ 1 / C_{o a} & 0\end{array}\right]$ and $G=\left[\begin{array}{cc}1 / L_{o a} & 0 \\ 0 & -1 / C_{o a}\end{array}\right]$.

Here, the voltages $\left(v_{o a}\right.$ and $\left.v_{a}\right)$, currents $\left(i_{o a}\right.$ and $\left.i_{a}\right)$, and filters $\left(L_{o a}, R_{o a}\right.$, and $\left.C_{o a}\right)$ are denoted in Fig. 3. $F$ and $G$ are the state space matrices. Based on (6), the zero-order-hold $(\mathrm{ZOH})$ based discretized model can be derived as

$$
\left[\begin{array}{c}
i_{\text {oa }}[k+1] \\
v_{a}[k+1]
\end{array}\right]=A\left[\begin{array}{c}
i_{\text {oa }}[k] \\
v_{a}[k]
\end{array}\right]+B\left[\begin{array}{c}
v_{o a}[k] \\
i_{a}[k]
\end{array}\right]
$$

where $A=e^{F \cdot T_{s}}$ and $B=\int_{0}^{T_{s}} e^{F \cdot \tau} d \tau \cdot G$.

Here $T_{\mathrm{s}}$ is the sampling time and the matrices $A$ and $B$ can be obtained from

$$
\begin{gathered}
A=\left[\begin{array}{ll}
A_{11} & A_{12} \\
A_{21} & A_{22}
\end{array}\right], \quad A_{11}=\frac{a \cdot e^{a \cdot T_{s}}-b \cdot e^{b \cdot T_{s}}}{a-b}, \\
A_{12}=\frac{-\left(e^{a \cdot T_{s}}-e^{b \cdot T_{s}}\right)}{L_{o a}(a-b)}, \quad A_{21}=\frac{e^{a \cdot T_{s}}-e^{b \cdot T_{s}}}{C_{a b}(a-b)} \\
A_{22}=\frac{a \cdot e^{a \cdot T_{s}}-b \cdot e^{b \cdot T_{s}}}{a-b}+\frac{R_{o a} \cdot\left(e^{a \cdot T_{s}}-e^{b \cdot T_{s}}\right)}{L_{o a}(a-b)} \\
B=\left[\begin{array}{ll}
B_{11} & B_{12} \\
B_{21} & B_{22}
\end{array}\right], B_{11}=\frac{e^{a \cdot T_{s}}-e^{b \cdot T_{s}}}{L_{o a}(a-b)}, \\
B_{22}=\frac{\left[\begin{array}{l}
a \cdot\left(e^{b \cdot T_{s}}-1\right)-b \cdot\left(e^{a \cdot T_{s}}-1\right)
\end{array}\right]}{\left(L_{o a} \cdot C_{o a} \cdot a \cdot b\right) \cdot(a-b)} \\
B_{12}=\frac{e^{b \cdot T_{s}}+R_{o a} \cdot\left[a-b-a \cdot e^{b \cdot T_{s}}+b \cdot e^{a \cdot T_{s}}\right.}{\left(L_{o a} \cdot C_{o a} \cdot a \cdot b\right) \cdot(a-b)}
\end{gathered}
$$


with $a, b=\frac{-R_{o a} / L_{o a} \pm \sqrt{\left(R_{o a} / L_{o a}\right)^{2}-4 / C_{o a} / L_{o a}}}{2}$.

Therefore, the future behavior of the output voltage $v_{a}$ can be predicted using

$$
v_{a}[k+1]=A_{21} \cdot i_{o a}[k]+A_{22} \cdot v_{a}[k]+B_{21} \cdot v_{o a}[k]+B_{22} \cdot i_{a}[k]
$$

which is derived from the discretized model (7). Similarly, the prediction model of input current $i_{S A}$ using the input filter model can be obtained in (11) to predict the future behavior of input current.

$$
i_{s A}[k+1]=M_{11} \cdot i_{s A}[k]+M_{12} \cdot v_{A}[k]+N_{11} \cdot v_{s A}[k]+N_{12} \cdot i_{A}[k]
$$

The matrices in (11) can be derived in a similar manner to (10). The dimension of the models can be reduced from the three-phase model to an $\alpha-\beta$ or $d-q$ model using frame transformations. Based on these predictions, MPC evaluates each switch state and selects the optimum one to be applied at the next sampling instant. This switch state should result in a minimum value of the cost function. Some variables in (10) and (11) can be measured using voltage and current transducers while some can be estimated using observers or calculated using switch matrices (1) and (2). The utilization of observers to estimate some variables can reduce the number of required sensors, thus the cost. The design of observers is described in the next section.

The output $L C$ filter can also be modeled in the block diagram as shown in Fig. 4 (a). Based on this figure, the transfer function of $v_{a}(s)$ to $v_{o a}(s)$ can be expressed as

$$
H(s)=\frac{v_{a}(s)}{v_{o a}(s)}=\frac{1}{L_{o a} C_{o a} s^{2}+R_{o a} C_{o a} s+1}
$$

Using (12), Bode plots are obtained for $H(s)$ with different values of $L_{o a}$ and $C_{o a}$ as shown in Fig. 4 (b). Here $R_{o a}$ is fixed to $0.5 \Omega$ while $L_{o a}$ and $C_{o a}$ are given in the legend, e.g., $(2,40)$ means $L_{o a}=2 \mathrm{mH}$ and $C_{o a}=40 \mu \mathrm{F}$. These Bode plots are related to Table II and Fig. 8 in Section V. As observed in these Bode plots, the magnitude responses are greater than zero at the targeted frequency $2 \times \pi \times 50 \mathrm{rad} / \mathrm{s}$, which means $v_{a}$ can be larger than $v_{o a}$; thus the VTR is improved. For instance, if the magnitude in the frequency domain is $0.5 \mathrm{~dB}$, the real filter gain is 1.06; therefore, the improved VTR is expected to reach $1.06 \times 0.866=0.918$. It is worth noting that the main purpose of output $L C$ filters in this work is to provide sinusoidal voltages instead of improving VTR.

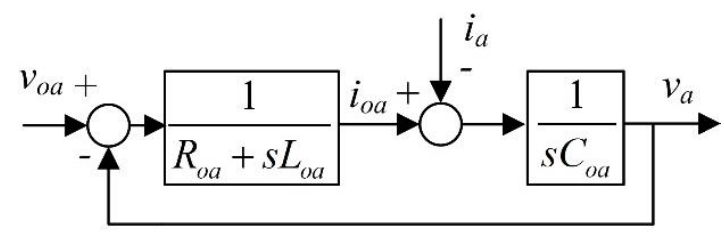

(a)

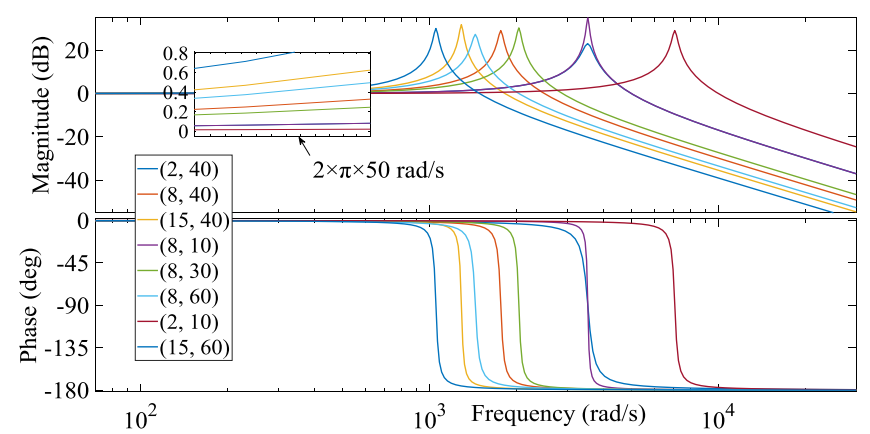

(b)

Fig. 4. Output filter model in block diagram and its Bode plots for different values of $L_{o a}$ and $C_{o a}(\mathrm{mH}, \mu \mathrm{F})$.

\section{OBSERVERS DESIGN}

An observer is a dynamic system that can estimate the states of a system. There are many observers that can be used to estimate the states of a system. The Luenberger observer is used in this work because of its simplicity and less effort in implementation. The models and measurements obtained from the MPC can be readily used in this observer. The Luenberger observer is also one of the classical observers and it can provide good performance.

For a system described in the state-space form Appendixes, if needed, appear before the acknowledgment.

$$
\begin{aligned}
& \dot{X}=F X+G U \\
& Y=C X+D U
\end{aligned}
$$

the Luenberger state observer can be designed to estimate the state $X$, as illustrated in

$$
\begin{gathered}
\dot{\hat{X}}=F \hat{X}+G U+L(Y-\hat{Y}) \\
\hat{Y}=C \hat{X}+D U
\end{gathered}
$$

where $\hat{X}$ and $\hat{Y}$ are the estimation of $X$ and output $Y$. Substituting (16) into (15) leads to

$$
\begin{aligned}
\dot{\hat{X}} & =F \hat{X}+G U+L(Y-\hat{Y}) \\
& =F \hat{X}+G U+L Y-L C \hat{X}-L D U \\
& =(F-L C) \hat{X}+(G-L D) U+L Y
\end{aligned}
$$

where $L$ is the observer gain matrix and can be computed by using Ackermann's formula based on the desired eigenvalues of the observer. The estimation error is $E=X-\hat{X}$ and its differential equation is $\dot{E}=\dot{X}-\dot{\hat{X}}=(F-L C) E$. The correct selection of gain matrix ensures that the error system is asymptotically stable so that the estimation error will finally decay to zero. Using (17), the observer diagram shown in Fig. 5 can be developed. 


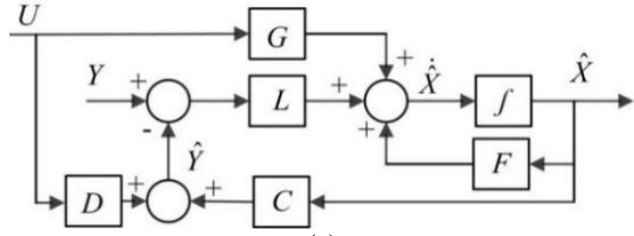

(a)

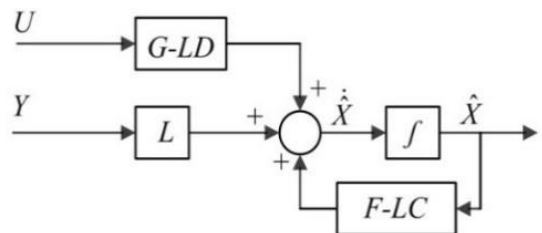

(b)

Fig. 5. Luenberger observer design diagram and the simplified diagram.

Depending on the specific observed state, the descriptions should be modified accordingly and some assumptions may be necessary. In order to observe the load current $i_{a}$, for example, the assumption $\mathrm{d} i_{a} / \mathrm{d} t=0$ is made and added to the model (6) to make either a 2-D or 3-D observer. This assumption is based on the fact that the sampling interval of the algorithm is usually sufficiently short, so the load current barely changes. Therefore, the modified model based on this assumption is obtained as a 3-D observer model in

$$
\begin{gathered}
\dot{X}_{o}=\left[\begin{array}{c}
i_{o a} \\
\dot{v}_{a} \\
i_{a}
\end{array}\right]=F_{o}\left[\begin{array}{c}
i_{o a} \\
v_{a} \\
i_{a}
\end{array}\right]+G_{o} U_{o}, Y_{o}=C_{o}\left[\begin{array}{c}
i_{o a} \\
v_{a} \\
i_{a}
\end{array}\right]+D_{o} U_{o}, \\
F_{o}=\left[\begin{array}{ccc}
-R_{o a} / L_{o a} & -1 / L_{o a} & 0 \\
1 / C_{o a} & 0 & -1 / C_{o a} \\
0 & 0 & 0
\end{array}\right], \\
G_{o}=\left[\begin{array}{lll}
1 / L_{o a} & 0 & 0
\end{array}\right]^{T}, U_{o}=v_{o a}
\end{gathered}
$$

Here, matrices $C_{o}$ and $D_{o}$ can be designed according to the desired outputs. Given that the system in (13) and (14) is observable, the gain matrix $L$ in (17) can be designed correctly so that eigenvalues of $F-L C$ are strictly on the left-hand side of the complex plane. Under this condition, the estimation error dynamics is asymptotically stable, which means the estimation error will decay to zero eventually. In this work, a 2-D observer is used because of simplicity and it can be derived in a manner similar to the 3-D observer. Load currents $i_{a, b, c}$ and source voltages $v_{S A, S B, S C}$ are estimated using the observers. The desired eigenvalues for estimating $i_{a, b, c}$ and $v_{s A, s B, s C}$ are set to $-2200 \pm 3800 i$ and -80000 and -80001 respectively. It is worth mentioning that the sampling time influences the performance of the observer since a discrete integrator is used. The shorter sampling time results in more accurate estimation.

The purpose of the observer is to serve as a sensor to provide the required signal. If the observer can provide a good estimation of the required signal, the stability of the MPC is not affected. It is worth mentioning that both the MPC and the observer are dependent on the system model. Therefore, their stabilities largely rely on model and parameter accuracy.

\section{Predictive Voltage Controller Design}

In the MPC, a cost function is employed to optimize the selection of switch actions. The design of cost function reflects the control objectives and priorities. In this work, the main control objective is the stable sinusoidal output voltages, in addition to unit input power factor, elimination of the common-mode voltage, and low switching frequency. Different combinations can be used depending on the specific applications. Therefore, the cost function for selecting the optimum switch state consists of four sub-functions and they are described in sequence by

$$
\begin{aligned}
g & =\lambda_{1} \cdot\left\{\left|v_{a}^{*}-v_{a}^{p}\right|+\left|v_{b}^{*}-v_{b}^{p}\right|+\left|v_{c}^{*}-v_{c}^{p}\right|\right\}+\lambda_{2} \cdot\left|Q^{*}-Q^{p}\right| \\
& +\lambda_{3} \cdot\left|v_{N}^{*}-v_{N}\right|+\lambda_{4} \cdot \sum_{i=1}^{9}\left|S_{i}-S_{i}^{p}\right|
\end{aligned}
$$

where $v_{a, b, c}^{*}$, and $Q^{*}$ are references for the three-phase output voltages and input reactive power and their counterparts $v_{a, b, c}^{p}$ and $Q_{p}$ are the predicted values; $v_{\mathrm{N}}$ represents the commonmode voltage shown in Fig. 3 and its desired reference $v^{*}{ }_{N}$ is normally zero; $S_{i}$ is the current switch state and $S_{i}^{p}$ is the potential switch state to be applied; and $\lambda_{1,2,3,4}$ are the weighting factors which determine priorities for each term. Terms with greater factors attract more control attention. The main control objective here is to have stable output sinusoidal voltages. If more control objectives are considered at the same time, each control performance will be compromised. Designing these factors is usually based on empirical methods [35]. The cost function is not limited to this form; other terms such as integral and square can also be used for meeting the requirements of different applications. The operation of absolute values in (19) consumes a great amount of execution time, and therefore they can be replaced by the square operation.

The voltage references should be determined according to the load requirements when it is used in an islanded DG system because the main objective is to maintain stable feed to loads. For a microgrid, with hierarchical control structure, the voltage references can be determined by the primary control using the droop characteristics [36] [37]. When a matrix converter is used in a microgrid, its hierarchical control structure (tertiary, secondary and primary control) can be designed in a similar manner to that of a VSI-dominated microgrid.

Here the input power factor control is achieved by regulating the reactive power as expressed in (19). The reactive power is calculated using

$$
Q=\frac{3}{2}\left(v_{S-\beta} \cdot i_{S-\alpha}-v_{S-\alpha} \cdot i_{S-\beta}\right), P=\frac{3}{2}\left(v_{S-\alpha} \cdot i_{S-\alpha}+v_{S-\beta} \cdot i_{S-\beta}\right)(20)
$$

where $Q$ and $P$ represent the reactive and active power. $v_{S-\alpha, \beta}$ and $i_{S-\alpha, \beta}$ represent the $\alpha$ and $\beta$ components of source voltages $v_{S A, S B, S C}$ and currents $i_{S A, S B, S C}$ and they are obtained using $a b c$ to $\alpha \beta$ transformation

$$
\left[\begin{array}{l}
u_{\alpha} \\
u_{\beta}
\end{array}\right]=\left[\begin{array}{ccc}
\frac{2}{3} & -\frac{1}{3} & -\frac{1}{3} \\
0 & -\frac{1}{\sqrt{3}} & -\frac{1}{\sqrt{3}}
\end{array}\right]\left[\begin{array}{l}
u_{a} \\
u_{b} \\
u_{c}
\end{array}\right]
$$




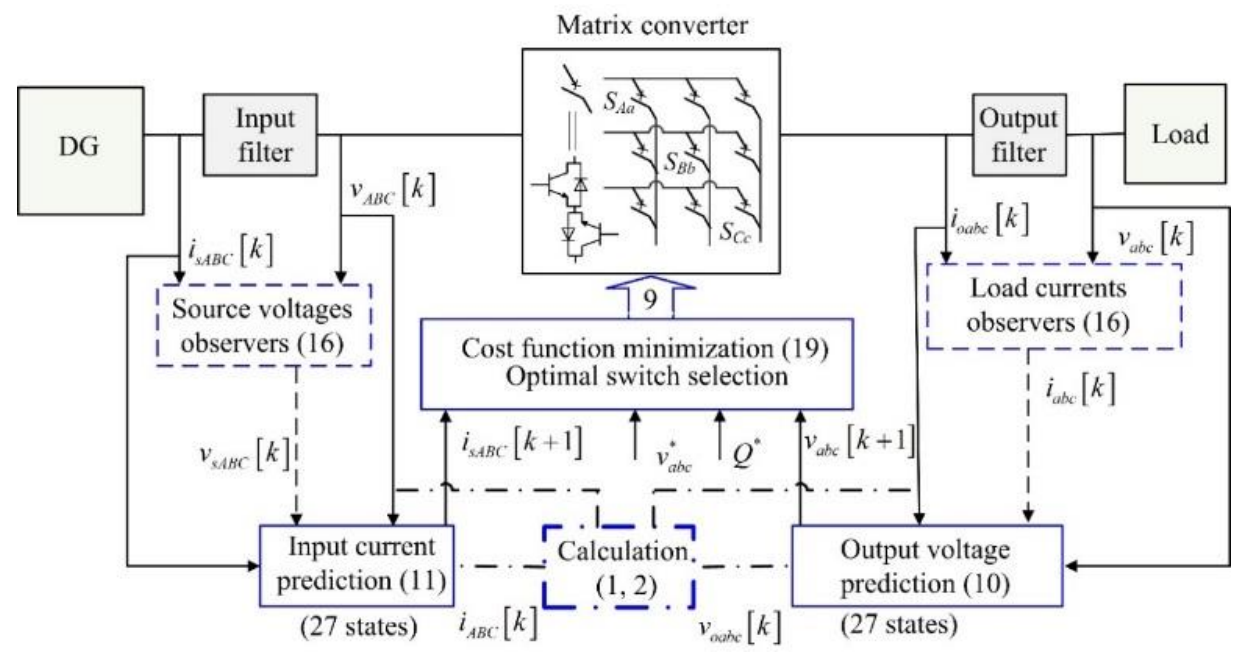

Fig. 6. The predictive voltage controller scheme for matrix converter in a DG system.

TABLE I SIMULATION SYSTEM AND CONTROLLER PARAMETERS.

\begin{tabular}{crrrrrrrrrr}
\hline$v_{s}\left[\mathrm{~V}_{\mathrm{pk}-\mathrm{pk}}\right]$ & $L_{A}[\mathrm{mH}]$ & $C_{A B}[\mu \mathrm{F}]$ & $R_{A}[\Omega]$ & $L_{o a}[\mathrm{mH}]$ & $C_{o a}[\mu \mathrm{F}]$ & $R_{o a}[\Omega]$ & $f_{s}[\mathrm{~Hz}]$ & $f_{o}[\mathrm{~Hz}]$ & $Q^{*}[\mathrm{VAr}]$ & $T_{s}[\mu \mathrm{s}]$ \\
\hline 100 & 6.8 & 9.5 & 0.5 & 8 & 40 & 0.5 & 50 & 50 & 0 & 80 \\
\hline
\end{tabular}

where $u_{\alpha, \beta}$ and $u_{a, b, c}$ stand for the variables in the $\alpha \beta$ and $a b c$ systems.

From the above descriptions, the model predictive voltage controller for the direct matrix converter in an islanded DG system can be illustrated by Fig. 6. In this figure, the measured variables are denoted by the solid arrow lines while the dashed arrow lines represent the observed variables. The calculated variables are shown by the dot-dashed lines. It is worth noting that the algorithm sample delay can be compensated in this controller [38].

Because MPC is a model based control strategy, its performance is affected by model parameter variation and mismatch. Many studies have investigated this issue and proposed possible solutions. These solutions include online parameter correction strategies and observer-based approaches. Some example solutions are adaptive online parameter identification based on least squares estimation [39], estimation using difference of magnitudes [40], discretetime disturbance observer [41] and sliding mode disturbance observer [42]. Since there are already many possible reported solutions, this issue is not investigated in this paper.

\section{Simulation Results}

In order to verify the proposed strategy, simulation tests were carried out and the results are shown in this section. The simulation parameters are tabulated in Table I. The peak-topeak amplitude of the source voltage is $100 \mathrm{~V}_{\mathrm{pk}-\mathrm{pk}}$. The MPC controller parameters for each test are shown in the figure captions for clarity. Since this paper focuses on the islanded operation mode, the stable voltages should be maintained under various load and input conditions. The execution time of the algorithm was around $61 \mu$ s and the sampling interval should be long enough for the code to be executed. As a result, a sampling time of $80 \mu$ s was used. In all the following figures, the black dashed voltage waveforms denote the voltage references.

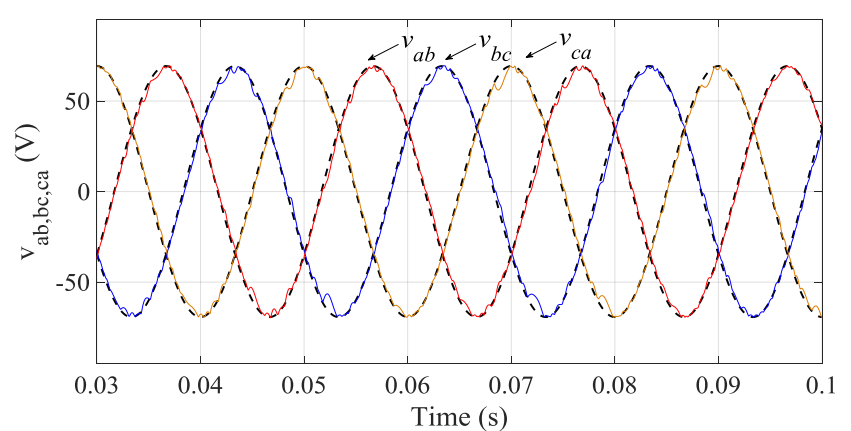

(a)

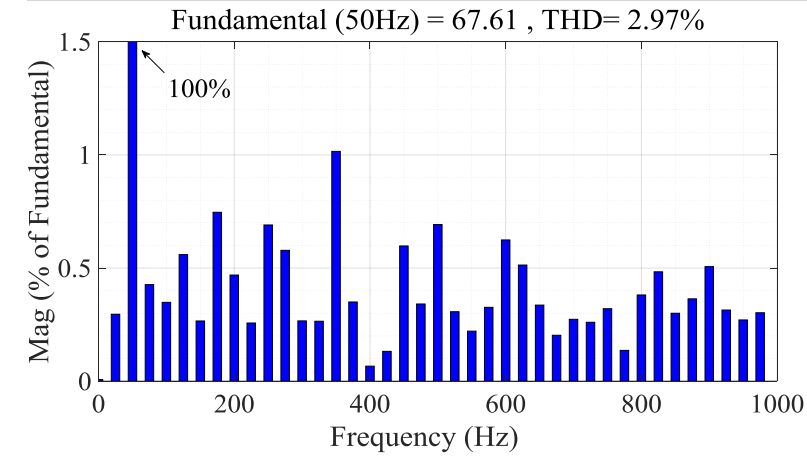

(b)

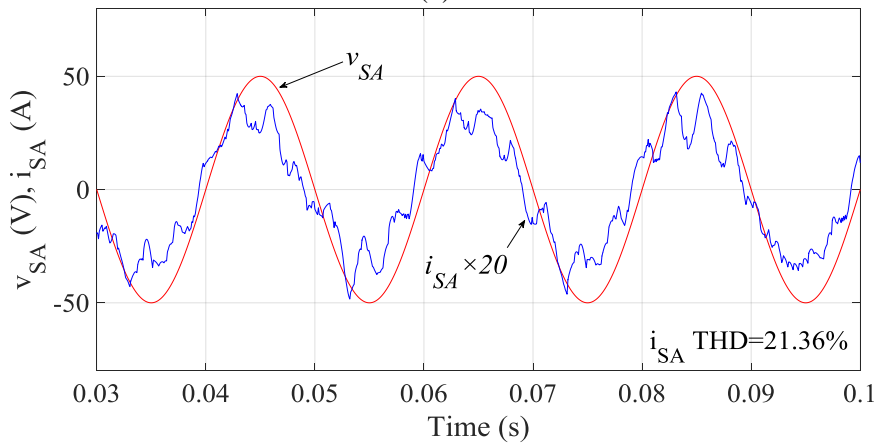

(c) 


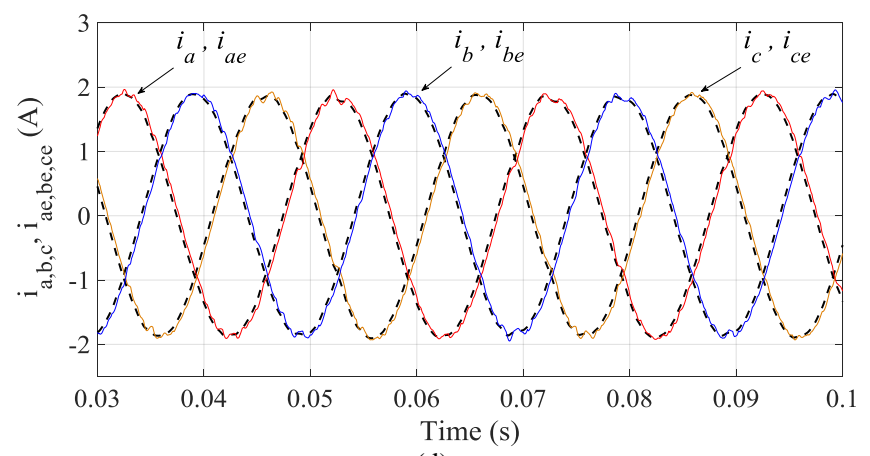

(d)

Fig. 7. Simulation results: (a) regulated output line-to-line voltages, (b) FFT analysis result and harmonic spectrum for $v_{a b}$, (c) source voltage and current waveforms, (d) estimated and measured load currents. $\left(\lambda_{1}=1, \lambda_{2}=0, \lambda_{3}=0\right.$, $\left.\lambda_{4}=0\right)$.

Fig. 7 shows the steady-state test results for an inductive load $\left(R_{l}=20 \Omega, L_{l}=14 \mathrm{mH}\right)$. The amplitude and frequency references for the output line-to-line voltages were set to $40 \times \sqrt{ } 3 \mathrm{~V}$ and $50 \mathrm{~Hz}$. Fig. 7 (a) shows the regulated three-phase output voltages and the fast Fourier transform (FFT) analysis is shown in Fig. 7 (b). As seen in the figure, the output voltages can be regulated to track the prescribed references effectively. In IEEE standard Std-519, the recommended harmonic voltage limits are $5 \%$ for the individual harmonic and $8 \%$ for the total harmonic distortion (THD). As seen in Fig. 7 (b), the regulated voltage satisfies these requirements. Fig. 7(c) shows the system source voltage and current. The input power factor is not regulated in this test, and therefore there exists an obvious phase difference between the voltage and current. The result of controlled input power factor will be shown later. Here, the input current is distorted because it is not controlled. Another reason for the distorted input current is the variable switching frequency resulting from the MPC. Therefore, if the input current waveform is regulated and the switching frequency is maintained constant, the input current quality can be improved significantly. SVM and modulated MPC can be used in this regard. An optimized filter design can also help improve the current quality [43]. Fig. 7 (d) compares the estimated load currents ( $i_{a e, b e, c e}$ - solid lines) and measured loads currents ( $i_{a, b, c}$ - dashed lines). A good match between the estimated and measured curves is achieved.

As analyzed in Section II, the output filter can help improve the VTR. Table II demonstrates the VTR performance for different values of $L_{o a}$ and $C_{o a}$ as previously studied in Section II. As seen in Table II, the VTR is larger than 0.866 for all cases presented in the table. Here the amplitude of the references is same as the amplitude of the source voltage. The fundamental amplitude of the output voltage is used when investigating the VTR. It is worth noting that the fundamental amplitude is normally lower than the peak amplitude. Therefore, the consideration of peak amplitude can lead to a slightly higher VTR. Increasing voltage references can also result in an increase in VTR while the distortions will deteriorate. The voltage waveforms corresponding to these cases are shown in Fig. 8. From these results, it is concluded that good voltage regulation performance with improved VTR can be achieved with the proposed strategy by selecting appropriate filter parameters.
TABLE II INVESTIGATION OF VTR VERSUS OUTPUT FILTER PARAMETERS.

\begin{tabular}{cccccc}
\hline Case & $\begin{array}{c}L_{o a} \\
{[\mathrm{mH}]}\end{array}$ & $C_{o a}[\mu \mathrm{F}]$ & $\begin{array}{c}\text { Fundamental } \\
\text { amplitude }[\mathrm{V}]\end{array}$ & VTR & THD [\%] \\
\hline 1 & 2 & 40 & 46.23 & 0.9246 & 4.79 \\
2 & 8 & 40 & 45.82 & 0.9164 & 5.55 \\
3 & 15 & 40 & 44.98 & 0.8996 & 5.43 \\
\hline 4 & 8 & 10 & 44.75 & 0.8950 & 6.56 \\
5 & 8 & 30 & 45.52 & 0.9104 & 5.98 \\
6 & 8 & 60 & 46.23 & 0.9246 & 4.27 \\
\hline 7 & 2 & 10 & 46.01 & 0.9202 & 8.77 \\
8 & 15 & 60 & 45.94 & 0.9188 & 3.89 \\
\hline
\end{tabular}

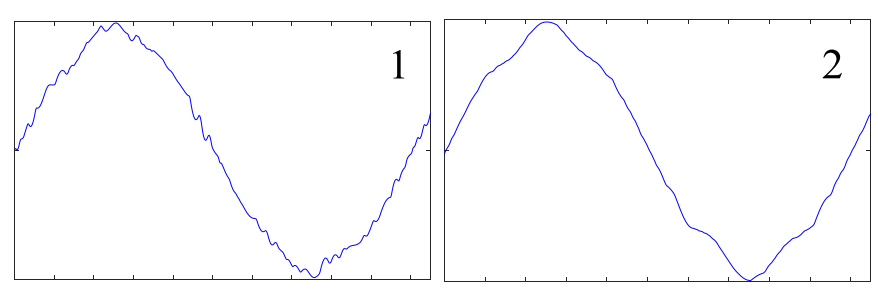

(a)

(b)

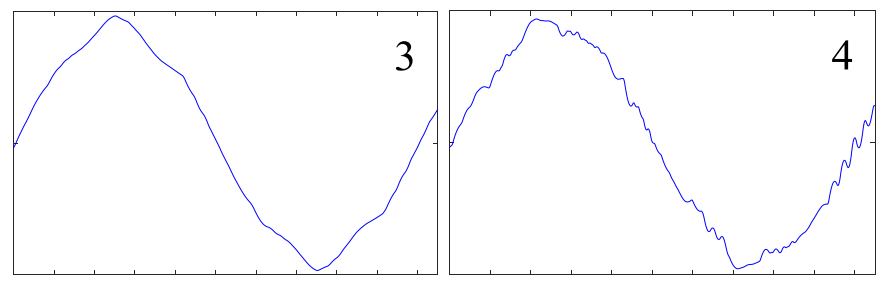

(c)

(d)

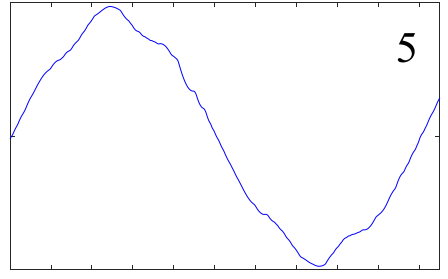

(e)

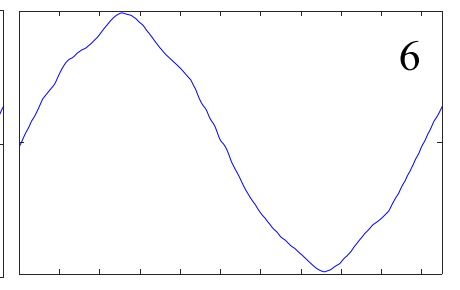

(f)

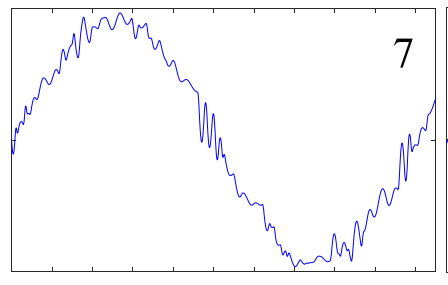

(g)

(h)

Fig. 8. Simulation results: output voltage waveforms corresponding to the parameter combinations listed in Table II.

In addition to the voltage regulation, the predictive control can also control the input power factor, common-mode voltage and the switching frequency. These results are presented in Fig. 9. The source voltage and current with the controlled input power factor are shown in Fig. 9 (a). As observed in this figure, the current is nearly in phase with the voltage. A unit power factor is achieved with the proposed controller. Compared with Fig. 7(c), the input current quality is substantially improved because the input power factor is controlled in this test. Fig. 9 (b) demonstrates the commonmode voltage reduction performance. From this figure, it is observed that the common-mode voltage is heavily 
suppressed. The common-mode voltage reduction is especially beneficial to motor loads. In MPC, rotating vectors are also utilized, which can contribute to common-mode voltage reduction [44]. Fig. 9 (c) compares the unregulated and regulated averaging switching frequencies of the switches. As we can see, the average switching frequency can be regulated effectively. The lower switching frequency can result in lower switching losses.

In a renewable source-based DG, the source voltage may suffer from an intermittent disturbance because of the discontinuity of a renewable energy source. This was simulated by adding the disturbance signal of $10 \times \sin (20 \pi t) \mathrm{V}$ to the source voltages. The source voltages and regulated output voltages are displayed in Fig. 9 (d). It can be concluded from this figure that the output voltage can be controlled effectively, although the source voltages are unbalanced and have disturbances. The proposed scheme was also tested under an unbalanced load and a nonlinear load. However, these results are not presented here because the regulated voltage waveforms are very similar to the results shown in Figs. 7 (a) and 9 (d). Instead, the corresponding experimental results will be shown in the next section. The simulation results in this section verify the feasibility of the proposed scheme and effectiveness of the proposed controller.

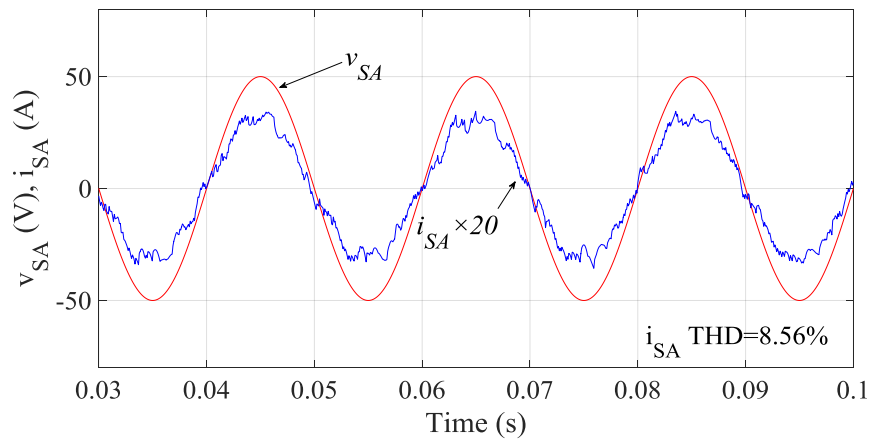

(a)
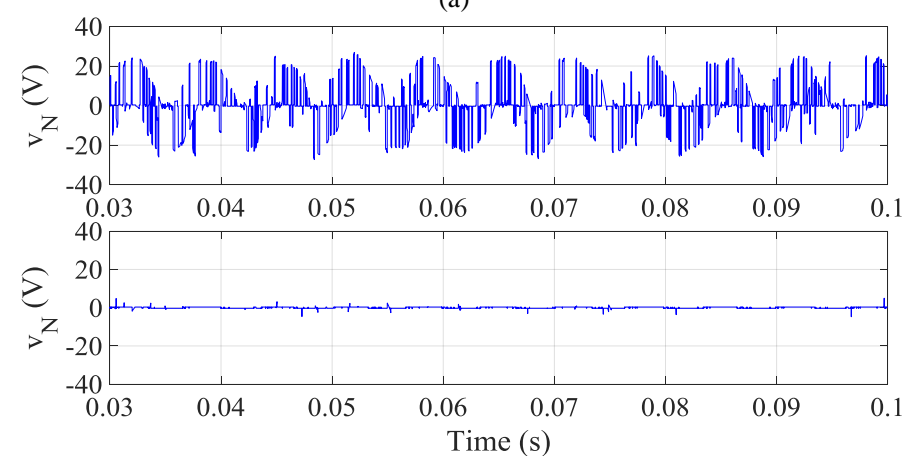

(b)

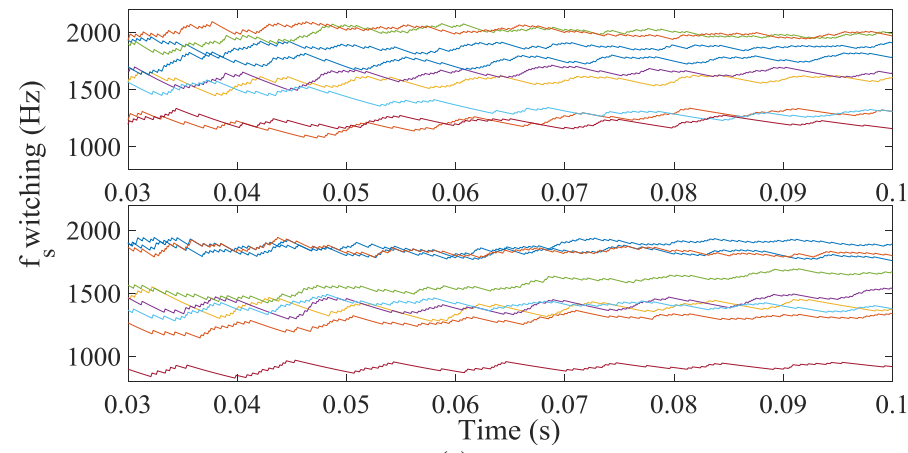

(c)

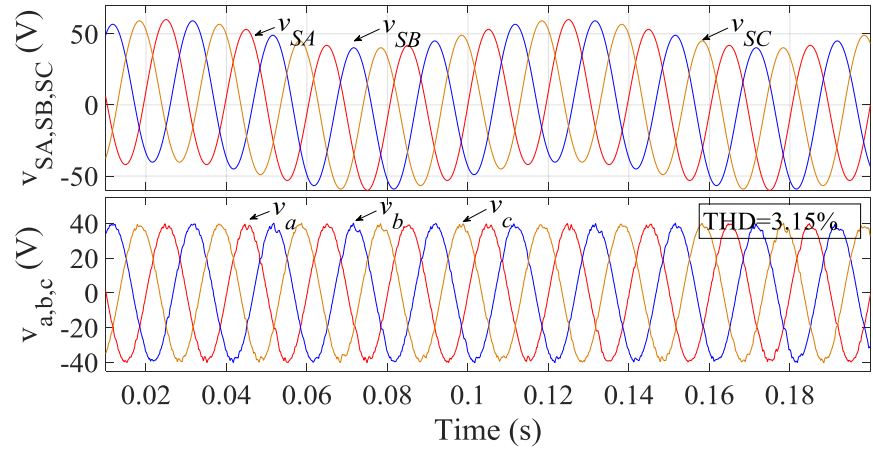

(d)

Fig. 9. Simulation results: (a) source voltage and current with controlled power factor with $\lambda_{2}=0.0067$, (b) uncontrolled and controlled common mode voltage with $\lambda_{3}=25$, (c) uncontrolled and controlled average switching frequencies with $\lambda_{4}=0.09$, (d) simulated intermittent source voltages and controlled output voltages.

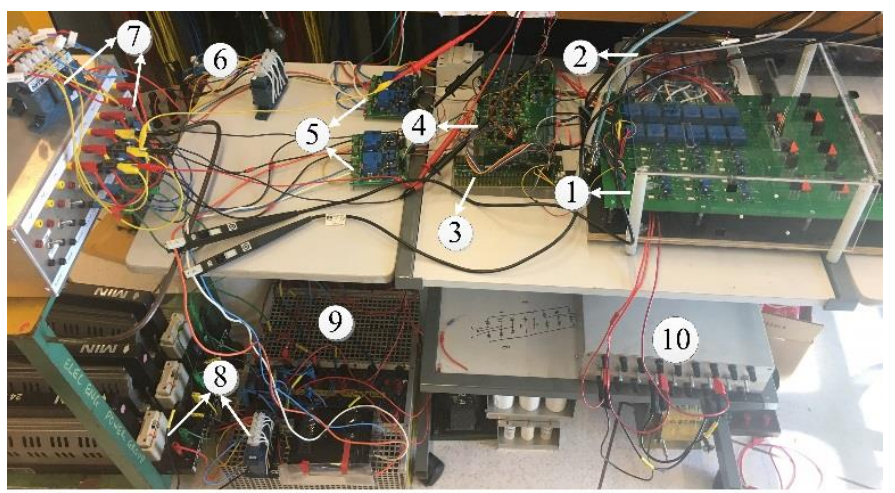

(a)

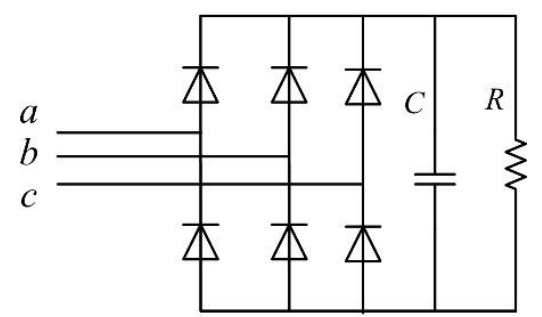

(b)

Fig. 10. Hardware setup for verifying the proposed scheme: (a) matrix converter system comprising (1) matrix converter prototype, (2) IGBT drivers power supply, (3) microprocessor control card, (4) ADC conditioning circuits, (5) sensors boards, (6) input filter inductors, (7) output $L C$ filters, (8) inductive loads, (9) clamp circuit, (10) input filter capacitors, (b) nonlinear load with $R=30 \Omega$ and $C=1700 \mu \mathrm{F}$.

\section{EXPERIMENTAL VALIDATION}

In order to further validate the feasibility and effectiveness of the proposed strategies, a matrix converter was built and the experimental work was carried out. The experiment set up is shown in Fig. 10 (a). Fig. 10 (b) shows the nonlinear load used to perform the nonlinear load test. A clamp circuit was used in the hardware to protect devices from overvoltage. The bidirectional switches (IGBTs) were arranged in the common collector configuration. As a result, only six independent DC driver power supplies are required for driving eighteen IGBTs. The control platform was a TI TMS320F28377D series digital signal processor (DSP) board and the real-time control implementation was carried out in MATLAB/Simulink with C2000 hardware support packages. A serial communication interface (SCI) was used for the communication between the 
host computer and DSP card for sending command and receiving data. The analog to digital conversion (ADC) and peripheral circuits were employed to process the signals from voltage and current sensors. The enhanced pulse width modulator (ePWM) blocks were used to generate the control pulses.

In the experimental tests, the amplitude and frequency of the output line-to-line voltages were set to $40 \times \sqrt{3} \mathrm{~V}$ and 50 $\mathrm{Hz}$. The reference voltages are denoted by the dashed lines in the following figures. Other system parameters are shown in Table I which are same as the simulation parameters unless elsewhere specified. Fig. 11 (a) to (c) show the regulated output voltage waveforms tracking the reference voltages at different frequencies $(25,100$ and $50 \mathrm{~Hz})$. The corresponding currents are shown in the bottom part of each figure. Here only two phases $\left(v_{a b}, v_{b c}\right.$ and $\left.i_{a}, i_{b}\right)$ are shown for clarity and the THD values are shown at the top-right corner for $v_{a b}$. These results demonstrate the effectiveness of the proposed controller in regulating the output voltage with a wide frequency range. The matrix converter can be employed to interface two systems that are greatly different in frequencies.

Fig. 11 (d) shows the experimental waveforms of the source voltage and current with uncontrolled input power factor. An obvious phase difference exists between the voltage and current. The results with the controlled input power factor will be shown in the later part of this section. Fig. 11 (e) displays the output voltage and currents responses to load connection. At the beginning, there is no load connected to the output terminals, so the load currents are zero. There is no obvious perturbation in the regulated voltages when the load is applied. In contrast, Fig. 11 (f) shows the responses to load disconnection. This figure verifies when the load is shed, the output voltage can be regulated effectively as well. The THD values in these results are low ranging from $4.55 \%$ to $5.11 \%$. The voltage quality in terms of harmonics distortion complies with the requirements in the IEEE standard Std-519.

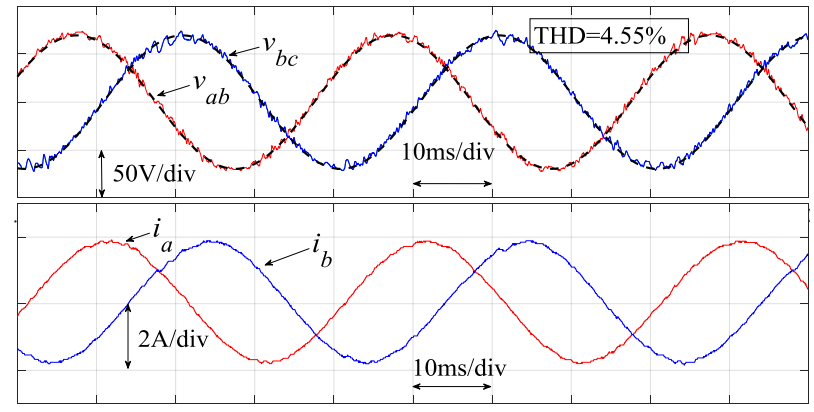

(a)

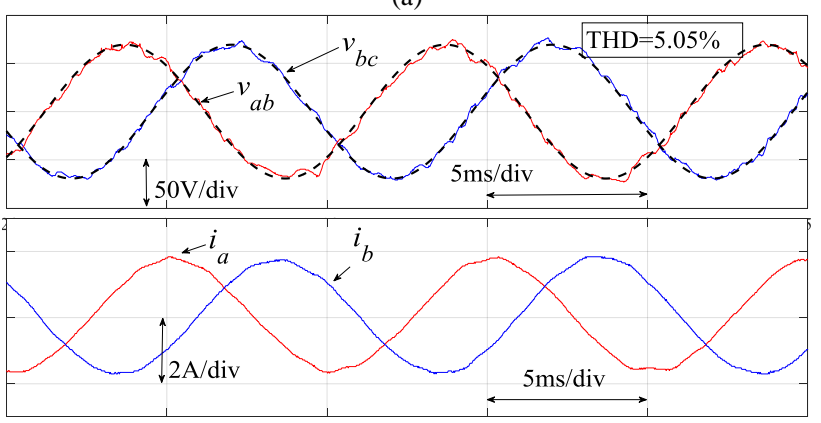

(b)

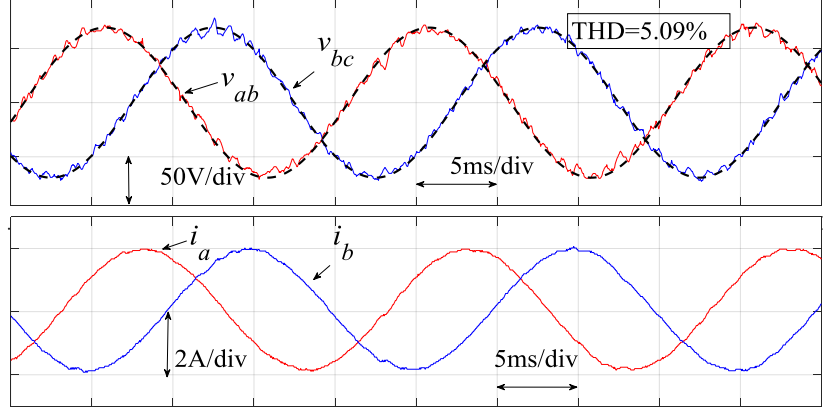

(c)

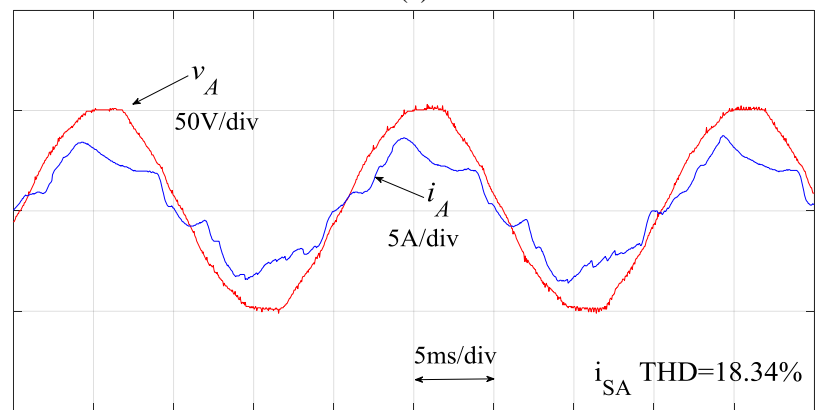

(d)

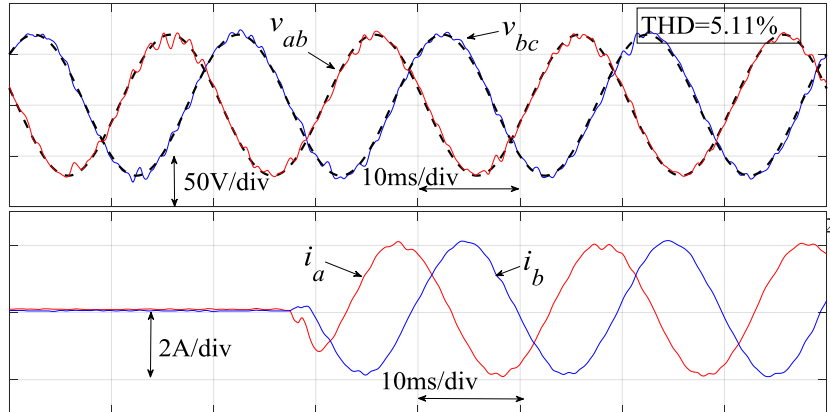

(e)

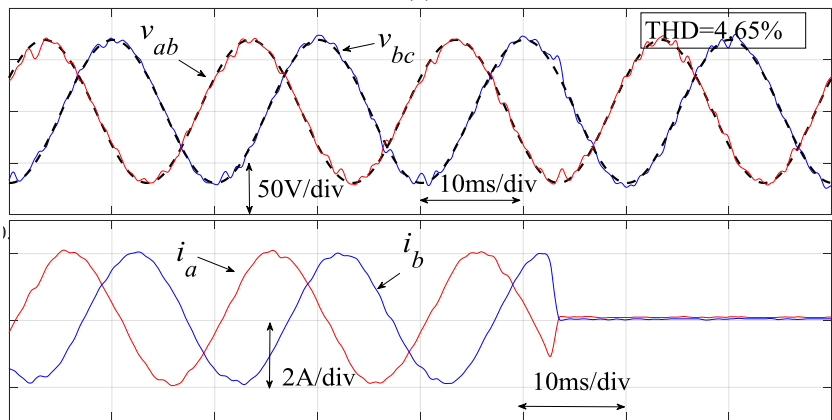

(f)

Fig. 11. Experimental waveforms: (a) output voltage and currents when $f_{o}=25$ $\mathrm{Hz}$, (b) output voltage and currents when $f_{o}=100 \mathrm{~Hz}$, (c) output voltage and currents when $f_{o}=50 \mathrm{~Hz}$, (d) source voltage and current when $f_{o}=50 \mathrm{~Hz}$, (e) output voltage and current responses to load connection, (f) output voltage and current responses to load disconnection. $\left(\lambda_{1}=1, \lambda_{2}=0, \lambda_{3}=0, \lambda_{4}=0\right)$.

In Fig. 12, the experimental results for the regulated input power factor and common-mode voltage are shown and compared with the unregulated waveforms. In Fig. 12 (a), the regulated input power factor is increased to 0.981 from 0.943 . The power factor was obtained from a FLUKE clamp meter. The power factor values shown in the figure are the averaged values based on several readings. This is because of the varying power factor caused by the current distortions. From Fig. 12 (b), it is evident that the common-mode voltage is suppressed dramatically. 


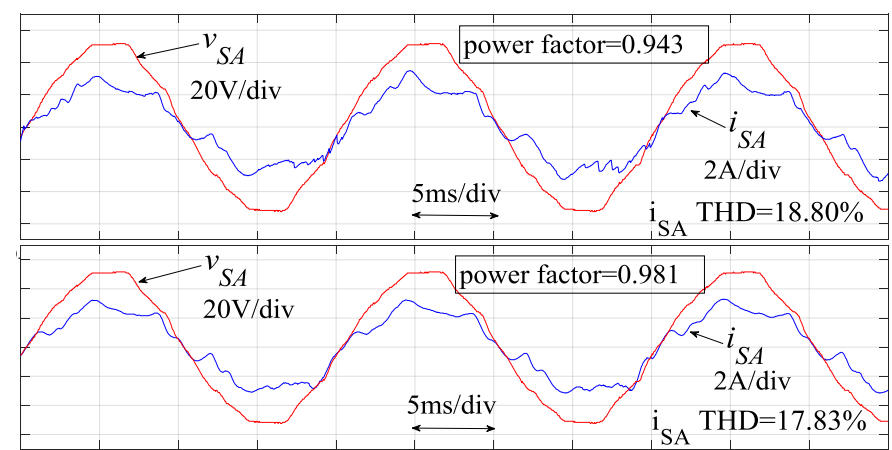

(a)

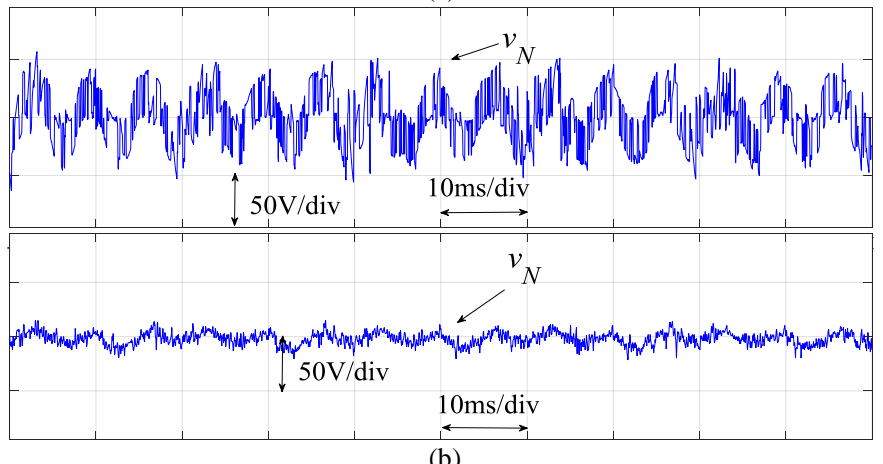

(b)

Fig. 12. Experimental waveforms: (a) uncontrolled and controlled input power factor with $\lambda_{2}=0.0067$, (b) uncontrolled and controlled common mode voltage with $\lambda_{3}=25$.

Fig. 13 presents the experimental results for nonlinear load, unbalanced load and unbalanced input tests. The nonlinear load used for Fig. 13 (a) was a three-phase diode bridge rectifier with a capacitive load, as shown in Fig. 10 (b). As shown in Fig. 13 (a), the output voltage can be regulated effectively under nonlinear load test. The output current is distorted in a manner similar to the current in common rectifier applications (even with ideal voltage supplies). The current can be improved with extra filters. Fig. 13 (b) shows the results of the unbalanced load test. For the unbalanced load test, the resistors for each phase were changed to 20, 12 and 8 $\Omega$ respectively while the inductors were kept at $14 \mathrm{mH}$.

Since it was not practical to implement the intermittent tests, tests under unbalanced input were performed instead. This is achieved by inserting a $5 \Omega$ resistor in phase $A$, between the source supply and the matrix converter. The resulted supply voltages are shown Fig. 13 (c) while the regulated output voltages and load currents are shown in Fig. 13 (d). As can be seen, a stable voltage is maintained even when the source is unbalanced.

The proposed scheme has been tested under various load and input conditions as described above. The experimental results verify that the output voltage can be effectively controlled to provide a stable and good quality voltage supply to different loads. The voltage harmonic distortions are under the limits set in IEEE Std-519.

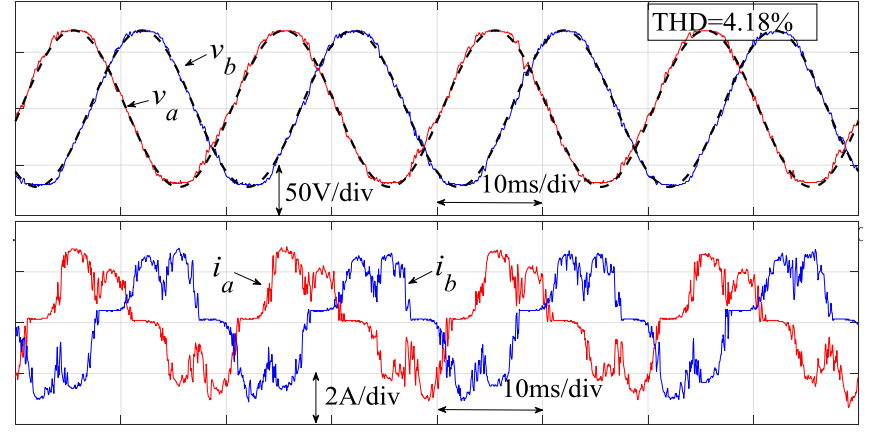

(a)

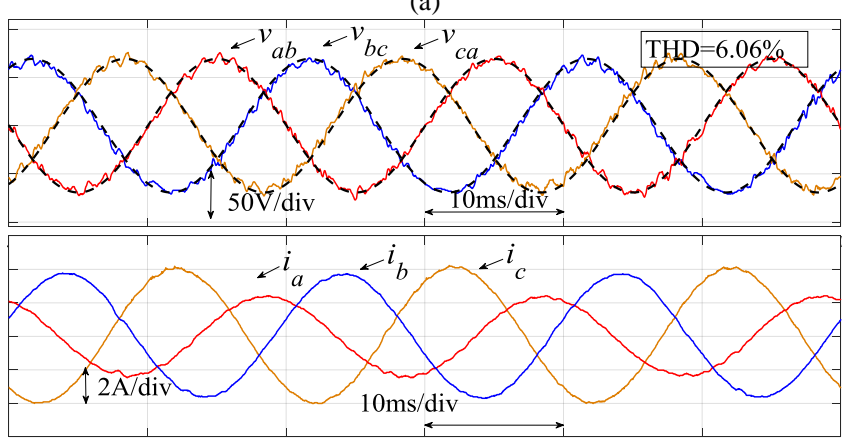

(b)

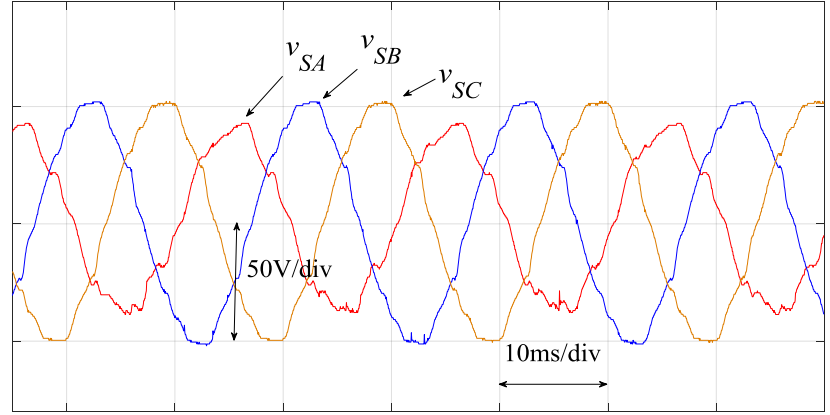

(c)

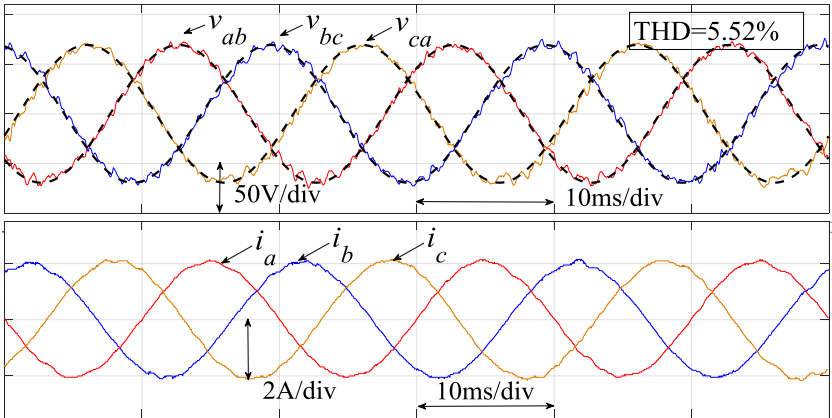

(d)

Fig. 13. Experimental waveforms: (a) output voltages and currents for nonlinear load test, (b) output voltages and currents for unbalanced load test, (c) input voltages for unbalanced input test, (d) output voltages and currents for unbalanced input test.

\section{CONCLUSION}

A matrix converter can fulfill direct $\mathrm{AC} / \mathrm{AC}$ conversion and it can be used to interface different systems with appropriate control strategies. This paper proposes a renewable energybased DG involving a direct matrix converter. The $L C$ filters are connected to the output terminals to provide a stable sinusoidal voltage supply to the load. This scheme has potential in microgrid applications. The predictive voltage control is developed and this involves various control objectives including sinusoidal output voltages, unit input 
power factor, common-mode voltage and averaging switching frequency reduction. The main control objective is to supply the stable voltage to various loads under various input and load conditions including unbalanced and nonlinear loads. A renewable energy based DG may suffer from the intermittent disturbance and unbalance which are also investigated in this work. Various tests validate the effectiveness of the matrix converter when applied in an islanded DG. The VTR is improved and it is supported by the theoretical analysis. Luenberger observers are adopted in the work to reduce the required number of sensors, thus the cost. Their effectiveness is verified when used in a predictive voltage controller. The simulation and experimental results verify the feasibility and effectiveness of the proposed strategy. The future work can include input current improvement, grid-connected mode and operation in a microgrid.

\section{REFERENCES}

[1] Y. Xia, W. Wei, M. Yu, X. Wang, and Y. Peng, "Power Management for a Hybrid AC/DC Microgrid with Multiple Subgrids," IEEE Trans. Power Electron., vol. 33, no. 4, pp. 3520-3533, 2018.

[2] H. Xiao, A. Luo, Z. Shuai, G. Jin, and Y. Huang, "An improved control method for multiple bidirectional power converters in hybrid AC/DC microgrid," IEEE Trans. Smart Grid, vol. 7, no. 1, pp. 340-347, 2016.

[3] J. Pegueroles-Queralt, F. D. Bianchi, and O.Gomis-Bellmunt, "A power smoothing system based on supercapacitors for renewable distributed generation," IEEE Trans. on Ind. Electron., vol. 62, no. 1, pp. 343-350, 2015.

[4] S. A. Saleh, E. Ozkop, and A. S. Aljankawey, "The Development of a Coordinated Anti-Islanding Protection for Collector Systems With Multiple Distributed Generation Units," IEEE Trans. Ind. Appl. vol. 52, no. 6, pp. 4656-4667, 2016.

[5] D. E. Olivares, A. Mehrizi-Sani, A. H. Etemadi, C. A. Canizares, R. Iravani, M. Kazerani, A. H. Hajimiragha et al., "Trends in microgrid control," IEEE Trans. smart grid, vol. 5, no. 4, pp. 1905-1919, 2014.

[6] X. Dou, K. Yang, X. Quan, Q. Hu, Z. Wu, B. Zhao, P. Li, S. Zhang and Y. Jiao. "An Optimal PR Control Strategy with Load Current Observer for a Three-Phase Voltage Source Inverter," Energies 8, no. 8, pp. 75427562, 2015.

[7] J. Huang, C. Jiang and R. Xu, "A review on distributed energy resources and MicroGrid," Renewable and Sustainable Energy Reviews, vol. 12, no. 9 , pp. 2472-2483, 2008.

[8] A. Trivedi and M. Singh, "Repetitive Controller for VSIs in Droop Based AC-Microgrid," IEEE Trans. Power Electron., vol. 32, no. 8, pp. 6595-6604, 2017.

[9] N. Hatziargyriou, H. Asano, R. Iravani, and C. Marnay, "Microgrids," IEEE power and energy mag., vol. 5, no. 4, pp. 78-94, 2007.

[10] B. Kroposki, R. Lasseter, T. Ise, S. Morozumi, S. Papatlianassiou, and N. Hatziargyriou, "Making microgrids work," IEEE power and energy mag., vol. 6, no. 3, pp. 41-53, 2008.

[11] N. Merritt, C. Chakraborty, and P. Bajpai, "New Voltage Control Strategies for VSC based DG Units in an Unbalanced Microgrid," IEEE Trans. Sustainable Energy, vol. 8, no. 3, pp., 1762-1770, 2017.

[12] J. Justo, F. Mwasilu, J. Lee and J. Jung, "AC-microgrids versus DCmicrogrids with distributed energy resources: A review." Renewable and Sustainable Energy Reviews, vol. 24, pp.387-405, 2013.

[13] L. Wang, D. Zhang, Y. Wang, B. Wu, and H. S. Athab, "Power and voltage balance control of a novel three-phase solid-state transformer using multilevel cascaded H-Bridge inverters for microgrid applications," IEEE Trans. Power Electron., vol. 31, no. 4, pp. 32893301, 2016.

[14] F. Bosio, L. Ribeiro, F. Freijedo, M. Pastorelli and J. Guerrero, "Discrete-Time Domain Modelling of Voltage Source Inverters in Standalone Applications: Enhancement of Regulators Performance by Means of Smith Predictor," IEEE Trans. Power Electron., DOI 10.1109/TPEL.2016.2632527, 2016.

[15] I. J. Balaguer, Q. Lei, S. Yang, U. Supatti, and F. Z. Peng, "Control for grid-connected and intentional islanding operations of distributed power generation," IEEE Trans. Ind. Electron., vol. 58, no. 1, pp. 147-157, 2011.
[16] P. Cortés, G. Ortiz, J. Yuz, J. Rodríguez, S. Vazquez and L. G. Franquelo, "Model predictive control of an inverter with output filter for UPS applications," IEEE Trans. on Ind. Electron., vol. 56, no. 6, pp. 1875-1883, 2009.

[17] A. Pirooz and R. Noroozian, "Predictive voltage control of three-phase voltage source inverters to supply nonlinear and unbalanced loads," 6th Drives Systems \& Technologies Conf. (PEDSTC), pp. 389-394, 2015.

[18] X. Liu, P. Loh, P. Wang, F. Blaabjerg, Y. Tang, and E. A. Al-Ammar, "Distributed generation using indirect matrix converter in reverse power mode," IEEE Trans. on Power Electron., vol. 28, no. 3, pp. 1072-1082, 2013.

[19] J. Zhang, L. Li, Z. Malekjamshidi, and D. G. Dorrell, "Predictive Voltage Control of Direct Matrix Converter with Reduced Number of Sensors for the Renewable Energy and Microgrid Applications," IEEE Energy Conversion Congress and Exposition (ECCE), Cincinnati, USA, pp. 3309-3315, Oct. 2017.

[20] P. Wheeler, J. Rodriguez, J. C. Clare, L. Empringham, and A. Weinstein, "Matrix converters: A technology review," IEEE Trans. on Ind. Electron., vol. 49, no. 2, pp. 276-288, 2002.

[21] J. Zhang, L. Li, D. Dorrell, and Yo. Guo, "A PI controller with current feedforward to improve the steady-state error performance for a current controlled direct matrix converter," 20th Int. Conf. Electrical Machines and Syst. (ICEMS), IEEE, pp. 1-6., 2017.

[22] G. Zhang, M. Su, Q. Zhu, and F. Blaabjerg, "A Predictive-ControlBased Over-Modulation Method for Conventional Matrix Converters," IEEE Trans. Power Electron., vol. 33, no. 4, pp. 3631 - 3643, 2018.

[23] J. Zhang, L. Li, and D. Dorrell, "Investigation of Direct Matrix Converter Working as a Versatile Converter (AC/AC, AC/DC, DC/AC, DC/DC Conversion) with Predictive Control," In 43rd Annual Conference Industrial Electronics Society, IEEE IECON 2017, Beijing, China, 2017.

[24] J. Zhang, D. G. Dorrell and L. Li, "Applications of the Direct Space Vector Modulation Controlled Matrix Converter as the Unified Power Flow Controller," The 8th Int. Conf. on Power Electron., Machines \& Drives (PEMD 2016), Glasgow, pp. 1-6, 2016.

[25] S. Arevalo, P. Zanchetta, P. W. Wheeler, A. Trentin, and L. Empringham, "Control and implementation of a matrix-converter-based AC ground power-supply unit for aircraft servicing," IEEE Trans. Ind. Electron., vol. 57, no. 6, pp. 2076-2084, 2010.

[26] P. Zanchetta, P. W. Wheeler, J. C. Clare, M. Bland, L. Empringham, and D. Katsis, "Control design of a three-phase matrix-converter-based acac mobile utility power supply." IEEE Trans. on Ind. Electron., vol. 55, no. 1, pp. 209-217, 2008.

[27] M. Hamouda, F. Fnaiech, K. Al-Haddad and H. Y. Kanaan, "Matrix converter control: A sliding mode approach." 30th Ann. Conf. Ind. Electron. Society (IECON 2004), vol. 3, pp. 2295-2300, 2004.

[28] S. M. Ahmed, H. Abu-Rub and Z. Salam, "Common-Mode Voltage Elimination in a Three-to-Five-Phase Dual Matrix Converter Feeding a Five-Phase Open-End Drive Using Space-Vector Modulation Technique," IEEE Trans. Ind. Electron., vol. 62, no. 10 pp. 6051-6063, 2015.

[29] J. Rodriguez, M. P. Kazmierkowski, J. R. Espinoza, P. Zanchetta, H. Abu-Rub, H. A. Young and C. A. Rojas, "State of the art of finite control set model predictive control in power electronics," IEEE Trans. Ind. Informatics, vol. 9, no. 2 pp. 1003-1016, 2013.

[30] S. Kouro, P. Cortés, R. Vargas, U. Ammann and J. Rodríguez, "Model predictive control-A simple and powerful method to control power converters," IEEE Trans. Ind. Electron., Vol. 56, no. 6, pp. 1826-1838, 2009.

[31] M. Rivera, C. Rojas, J. Rodríguez, P. Wheeler, B. Wu, and J. R. Espinoza, "Predictive current control with input filter resonance mitigation for a direct matrix converter," IEEE Trans. Power Electron., vol. 26, no. 10, pp. 2794-2803, 2011.

[32] M. Rivera, A. Wilson, C. A. Rojas, J. Rodriguez, J. R. Espinoza, P. W. Wheeler, and L. Empringham, "A comparative assessment of model predictive current control and space vector modulation in a direct matrix converter." IEEE Trans. on Ind. Electron., vol. 60, no. 2, pp. 578-588, 2013.

[33] S. Vazquez, J. I. Leon, L. G. Franquelo, J. Rodriguez, H. A. Young, A. Marquez, and P. Zanchetta, "Model predictive control: A review of its applications in power electronics," IEEE Ind. Electron. Magazine, vol. 8, no. 1, pp. 16-31, 2014.

[34] IEEE Recommended Practice and Requirements for Harmonic Control in Electric Power Systems, IEEE Standard: IEEE Std 519 ${ }^{\mathrm{TM}}-2014$ (Revision of IEEE Std 519-1992). 
[35] P. Cortés, S. Kouro, B. L. Rocca, R. Vargas, J. Rodríguez, J. I. León, S. Vazquez and L. G. Franquelo, "Guidelines for weighting factors design in model predictive control of power converters and drives," Int. Conf. Ind. Tech. (ICIT 2009), pp. 1-7, 2009.

[36] A. Bidram, and Ali Davoudi, "Hierarchical structure of microgrids control system," IEEE Trans. Smart Grid, vol. 3, no. 4, pp. 1963-1976, 2012.

[37] J. P. Lopes, C. L. Moreira, and A. G. Madureira, "Defining control strategies for microgrids islanded operation," IEEE Trans. Power Syst., vol. 21, no. 2, pp. 916-924, 2006.

[38] P. Cortes, J. Rodriguez, C. Silva and A. Flores, "Delay compensation in model predictive current control of a three-phase inverter," IEEE Trans. Ind. Electron., vol. 59, no. 2, pp. 1323-1325, 2012.

[39] S. Kwak, U. Moon, and J. Park, "Predictive-control-based direct power control with an adaptive parameter identification technique for improved AFE performance," IEEE Trans. Power Electron., vol. 29, no. 11, pp. 6178-6187, 2014.

[40] B. Arif, L. Tarisciotti, P. Zanchetta, J. C. Clare, and M. Degano, "Grid parameter estimation using model predictive direct power control," IEEE Trans. Ind. Appl., vol. 51, no. 6, pp. 4614-4622, 2015.

[41] H. Yang, Y. Zhang, J. Liang, N. Zhang, and W. Paul, "A robust deadbeat predictive power control with sliding mode disturbance observer for PWM rectifiers," IEEE Energy Conversion Congress and Exposition (ECCE 2017), pp. 4595-4600, 2017.

[42] H. Yang, Y. Zhang, J. Liang, N. Zhang, and W. Paul, "Robust Deadbeat Predictive Power Control with a Discrete-time Disturbance Observer for PWM Rectifiers under Unbalanced Grid Conditions," IEEE Trans. Power Electron., DOI: 10.1109/TPEL.2018.2816742, 2018.

[43] A. K. Sahoo, K. Basu, and N. Mohan, "Systematic Input Filter Design of Matrix Converter by Analytical Estimation of RMS Current Ripple," IEEE Trans. Ind. Electron., vol. 62, no. 1, pp. 132-143, 2015.

[44] S. Tewariand N. Mohan, "Matrix converter based open-end winding drives with common-mode elimination: Topologies, analysis, and comparison," IEEE Trans. Power Electron., vol. 33, no. 10, pp. $8578-$ 8595, 2018.

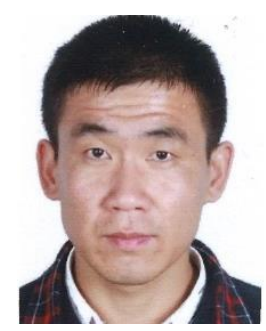

Jianwei Zhang (S'15) received his bachelor degree in electrical engineering from the Northwest A\&F University, Yangling, Shaanxi, China, in 2014. Since then, he has been working towards his Ph.D. degree in electrical engineering at the University of Technology Sydney (UTS), Sydney, New South Wales, Australia. From 2015, he has been working as a Casual Academic at the Faculty of Engineering and IT, UTS.

His research interests include control of power electronic converters, matrix converters, microgrids and $\mathrm{AC}$ motor drives.

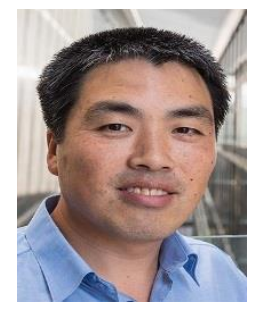

Li Li (M'12) was born in Henan, China. He received his B.S. degree from Huazhong University of Science and Technology in 1996, M.S. degree from Tsinghua University in 1999, and Ph.D. degree from University of California, Los Angeles in 2005.

From 2005 to 2007, he was a research associate at the University of New South Wales at the Australian Defence Force Academy (UNSW@ADFA). From 2007 to 2011, he was a researcher at the National ICT Australia, Victoria Research Laboratory, Department of Electrical and Electronic Engineering, The University of Melbourne. He joined UTS in 2011 and currently he is an Associate Professor. Dr. Li held several visiting positions at Beijing Institute of Technology, Tsinghua University and UNSW@ADFA. His research interests are control theory and power system control.

His interests are control theory and power system control.

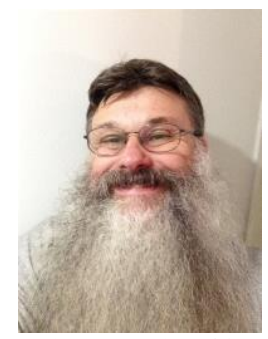

David G. Dorrell (M'95-SM'08) is a native of St. Helens, U.K. He received the B.Eng. (Hons.) degree in electrical and electronic engineering from the University of Leeds, Leeds, U.K., in 1988; the M.Sc. degree in power electronics engineering from the University of Bradford, Bradford, U.K., in 1989; and the Ph.D. degree in engineering from the University of Cambridge, Cambridge, U.K., in 1993.

Since 2015, he has been Professor of Electrical Machines with the University of KwaZulu-Natal, Durban, South Africa. He is also the Director of the EPPEI Specialization Centre of HVDC and FACTS, UKZN. He has held lecturing positions at Robert Gordon University, Aberdeen, U.K., and the University of Reading, Reading, U.K. He was a Senior Lecturer at the University of Glasgow, Glasgow, U.K., for several years. In 2008, he took up a post as a Senior Lecturer at the University of Technology Sydney, Ultimo, NSW, Australia, and he was promoted to an Associate Professor in 2009. He is also an Adjunct Associate Professor with National Cheng Kung University, Tainan, Taiwan. His research interests include the design and analysis of various electrical machines, and also renewable energy systems.

Dr. Dorrell is a Chartered Engineer in the U.K. and also a fellow of the Institution of Engineering and Technology.

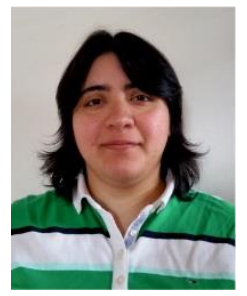

Margarita Norambuena (S'12-M'14) received the B.S. and M. S. degrees in electric engineering from the Universidad Tecnica Federico Santa Maria (UTFSM), Valparaiso, Chile, in 2013. She received the Ph.D. degree (summa cum laude) in electronics engineering from the UTFSM and Technische Universitaet Berlin (TUB) in 2017. She received a scholarship from Chilean National Research, Science and Technology Committee (CONICYT) in 2014 to pursue the $\mathrm{PhD}$ degree studies in power electronics at UTFSM and Technische Universitaet Berlin (TUB). She also received a scholarship from German Academic Exchange Service (DAAD) in 2015 to pursue the PhD degree studies in TUB.

From 2015 to 2018, she was an Assistant Professor at Universidad Andres Bello, Santiago, Chile. Currently, she is an Associate Professor at Universidad Técnica Federico Santa María, Santiago, Chile.

Her research interest include multilevel converters, model predictive control of power converters and drives, energy storage systems, renewable energy and microgrids systems.

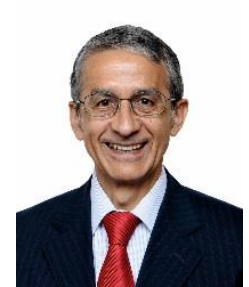

Jose Rodriguez (M'81-SM'94-F'10) received the Engineer degree in electrical engineering from the Universidad Tecnica Federico Santa Maria, in Valparaiso, Chile, in 1977 and the Dr.-Ing. degree in electrical engineering from the University of Erlangen, Erlangen, Germany, in 1985. He has been with the Department of Electronics Engineering, Universidad Tecnica Federico Santa Maria, since 1977, where he was full Professor and President. Since 2015 he is the President of Universidad Andres Bello in Santiago, Chile. He has coauthored two books, several book chapters and more than 400 journal and conference papers. His main research interests include multilevel inverters, new converter topologies, control of power converters, and adjustable-speed drives. He has received a number of best paper awards from journals of the IEEE. Dr. Rodriguez is member of the Chilean Academy of Engineering. In 2014 he received the National Award of Applied Sciences and Technology from the government of Chile. In 2015 he received the Eugene Mittelmann Award from the Industrial Electronics Society of the IEEE. 